\title{
Successful atrioventricular valve repair improves long-term outcomes in children with unbalanced atrioventricular septal defect
}

\author{
Edward Buratto, MBBS, Xin Tao Ye, MD, Christian P. Brizard, MD, MS, Johann Brink, MBChB, FRACS, \\ Yves d'Udekem, MD, PhD, FRACS, and Igor E. Konstantinov, MD, PhD, FRACS
}

\section{ABSTRACT}

Background: Atrioventricular valve regurgitation is a significant cause of morbidity and mortality in patients with unbalanced atrioventricular septal defect. However, knowledge of the outcomes of atrioventricular valve repair in children with unbalanced atrioventricular septal defect and univentricular physiology is limited.

Methods: We conducted a retrospective review of all patients with unbalanced atrioventricular septal defect treated with single-ventricle palliation who underwent atrioventricular valve surgery at The Royal Children's Hospital.

Results: Between 1976 and 2016, 139 children with unbalanced atrioventricular septal defect underwent single-ventricle palliation, of whom 31.7\% (44/139) required atrioventricular valve surgery. Repair of the atrioventricular valve was attempted in $97.7 \%$ (43/44) of patients, of whom $4.7 \%(2 / 43)$ were converted to replacement during the initial operation. Replacement of the atrioventricular valve without attempted repair was performed in $2.3 \%(1 / 44)$ of patients. Early mortality was $18.2 \%(8 / 44)$. Freedom from death or transplantation at 10 years was $66.0 \%$ (95\% confidence interval, 49.1-78.5) and at 20 years was $53.3 \%$ (95\% confidence interval, 32.1-70.6). In multivariable analysis, significant predischarge atrioventricular valve regurgitation (hazard ratio, $6.4 ; P=.002$ ), age less than 1 year (hazard ratio, $8.3 ; P=.01$ ), and repair before stage II palliation (hazard ratio, 3.4; $P=.04$ ) were associated with death. Freedom from reoperation at 10 years was $61.9 \%$ (95\% confidence interval, 41.9-76.8) and at 20 years was 56.3\% (95\% confidence interval, 35.3-72.8). Moderate or greater atrioventricular valve regurgitation at discharge was associated with an increased risk of reoperation (hazard ratio, $1.8 ; P=.03$ ). Of transplant-free survivors, atrioventricular valve regurgitation was less than moderate in $60.0 \%$ $(15 / 25)$ at the most recent follow-up.

Conclusions: Atrioventricular valve surgery in patients with unbalanced atrioventricular septal defect is associated with substantial mortality and a high rate of reoperation. Successful atrioventricular valve repair is associated with better survival and freedom from reoperation. ( $\mathrm{J}$ Thorac Cardiovasc Surg 2017;154:2019-27)

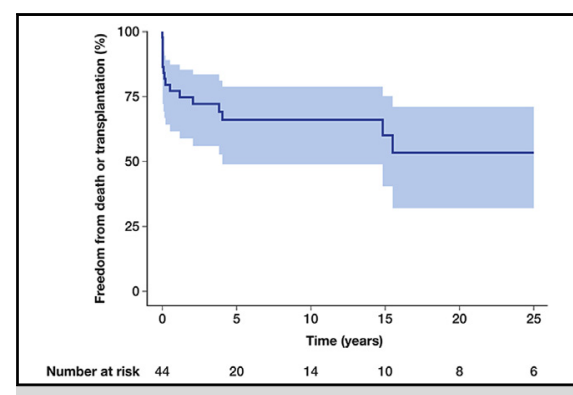

Freedom from death or transplantation after AW repair in children with UAVSD.

\section{Central Message}

AVV surgery in children with uAVSD is challenging, with a high risk of mortality and reoperation. However, successful repair is associated with better outcomes.

\section{Perspective}

Children with uAVSD who require AVV surgery have high rates of reoperation and death, with only half of patients surviving at 20 years. Successful AVV repair is associated with better survival, whereas significant residual regurgitation is associated with a poor prognosis, and these patients may benefit from AVV replacement.

See Editorial Commentary page 2028.

\footnotetext{
From the Department of Cardiothoracic Surgery, The Royal Children's Hospital, Melbourne; Department of Paediatrics, The University of Melbourne, Melbourne; and Murdoch Children's Research Institute, Melbourne, Australia.

This project was supported by the Victoria Government's Operational Infrastructure Support Program. E.B. is a recipient of a Reg Worcester Scholarship from the Royal Australasian College of Surgeons and a Postgraduate Scholarship from the National Health and Medical Research Council (1134340). Y.d'U. is a National Health and Medical Research Council Clinician Practitioner Fellow (1082186).
}

Received for publication Nov 28, 2016; revisions received May 25, 2017; accepted for publication June 19, 2017; available ahead of print July 22, 2017.

Address for reprints: Igor E. Konstantinov, MD, PhD, FRACS, Royal Children's Hospital, Flemington Rd, Parkville, Victoria 3029, Australia (E-mail: igor: konstantinov@rch.org.au). 0022-5223/ $\$ 36.00$

Crown Copyright $\odot 2017$ Published by Elsevier Inc. on behalf of The American Association for Thoracic Surgery

http://dx.doi.org/10.1016/j.jtcvs.2017.06.042 


\section{Abbreviations and Acronyms}

AVSD $=$ atrioventricular septal defect

$\mathrm{AVV}=$ atrioventricular valve

AVVR $=$ atrioventricular valve regurgitation

$\mathrm{CI}=$ confidence interval

ePTFE $=$ expanded polytetrafluoroethylene

SHR = subhazard ratio

SVP $=$ single-ventricle palliation

$\mathrm{uAVSD}=$ unbalanced atrioventricular septal defect

Scanning this QR code will take you to the article title page.

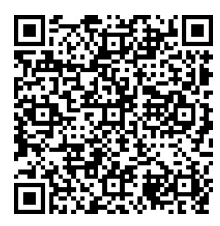

Unbalanced atrioventricular septal defect (uAVSD) constitutes approximately $10 \%$ of all atrioventricular septal defects (AVSDs). ${ }^{1}$ When biventricular repair is not feasible, these children require single-ventricle palliation (SVP), which is associated with substantial mortality and morbidity. ${ }^{2,3}$ Atrioventricular valve (AVV) regurgitation (AVVR) is a major cause of morbidity in these patients, with up to one third requiring an AVV procedure. ${ }^{2,3}$ In the setting of SVP, AVVR is a recognized risk factor for death. $^{4-6}$ Furthermore, achieving an adequate, durable AVV repair in patients with single-ventricle physiology is challenging. ${ }^{7-10}$ However, reports of AVV repair in patients with uAVSD have been limited to a few small series. ${ }^{11,12}$

\section{MATERIALS AND METHODS Patients}

All patients with uAVSD who underwent SVP and required at least 1 AVV operation at The Royal Children's Hospital, Melbourne from January 1, 1976, to January 1, 2016, were included in this study. Ethics approval was granted by The Royal Children's Hospital Human Research Ethics Committee (32047E). International patients were excluded because follow-up data were not available for this group.

Unbalanced AVSD was defined as a complete AVSD, as confirmed on echocardiography, which in the opinion of the treating team was not suitable for biventricular repair (ie, the ventricles could not be septated). The reasons for this were a hypoplastic ventricle or a straddling AVV.

Baseline data were collected by retrospective chart review. Follow-up data were obtained by correspondence with the patients' general practitioners and cardiologists. Follow-up was complete if the last confirmed patient contact occurred within 2 years of the end of the study period. Early death was defined as death occurring within 30 days of surgery or before discharge from hospital.

The degree of AVVR was graded by echocardiography on an ordinal scale $(0=$ none, $1=$ trivial, $2=$ mild, $3=$ moderate, $4=$ severe $)$. Significant AVVR was considered to be present when AVVR was moderate or greater.
Ventricular dysfunction was defined as moderate or greater dysfunction of the dominant ventricle as reported on echocardiography immediately before AVV repair. The mechanism of AVVR was determined by reviewing preoperative and intraoperative echocardiography reports.

\section{Operative Technique}

The techniques used to perform AVV repair were chosen by the operating surgeon at the time of the procedure on the basis of operative findings and echocardiography. Three primary techniques have been adopted over the study period. The earliest repairs were performed using a suture annuloplasty (de Vega type). During the intermediate period, repairs were performed using the "edge-to-edge" technique. In this procedure, the central facing edges of the superior and inferior bridging leaflets were approximated with interrupted Prolene sutures, creating a double orifice valve. More recently, a bridging strip of expanded polytetrafluoroethylene (ePTFE) (Gore-Tex Inc, Flagstaff, Ariz) was used to facilitate edge-to-edge repair. This technique has been described and illustrated in detail. ${ }^{9,10}$ The central facing parts of the superior and inferior bridging leaflets were approximated with interrupted Prolene sutures. The distance from the base of the inferior bridging leaflet to the base of the superior bridging leaflet was measured. A strip of ePTFE was then cut to size and sutured to the annulus with interrupted ePTFE sutures and to the leaflets using interrupted Prolene stitches. Additional repair techniques including the insertion of ePTFE neochordae and closure of accessory clefts were performed as required, using techniques previously described in detail. ${ }^{13}$

\section{Statistical Methods}

All data were analyzed using STATA version 13 (StataCorp LP, College Station, Tex). All continuous data are expressed as mean \pm standard deviation unless otherwise specified. Continuous data were compared between groups using the Mann-Whitney $U$ test. Discrete variables were compared between groups using the chi-square test, unless group size was less than 10, in which case the Fisher exact test was used. The degrees of preoperative and postoperative AVVR were compared using the paired 2-tailed Student $t$ test. Time-dependent end points, survival, and freedom from death and transplantation were analyzed using the Kaplan-Meier method, with time commencing at the time of AVV surgery. In addition, a competing risk analysis was performed for survival (with transplantation as a competing risk) and reoperation (with death and transplantation as competing risks). Univariable regression analysis of risk factors for death or reoperation was performed using a Fine and Gray's proportional subhazard model to account for competing risk. The factors entered into the model were age less than 1 year, significant preoperative AVVR, significant AVVR at discharge, AVV surgery before stage II palliation, dominant right ventricle, AVV repair with the ePTFE bridge technique, requirement for permanent pacemaker in the early postoperative period, total anomalous pulmonary venous drainage, edge-to-edge repair technique (including both patients with conventional edge-to-edge repair and ePTFE bridge), ventricular dysfunction, and year of operation (measured in days after the first AVV repair in this series, scaled to years). Factors with moderate evidence against the null hypothesis $(P<.10)$ were entered into a multivariable model. The variables included in the multivariable analysis were significant predischarge AVVR, age less than 1 year, and repair before stage II palliation.

\section{RESULTS \\ Demographics}

A total of 44 patients underwent AVV surgery during the study period (Figure 1). Baseline demographics are shown in Table 1. Infants accounted for $34.1 \%$ (15/44) of patients, including 3 neonates $(6.8 \%, 3 / 44)$. There was a high rate of associated defects, particularly heterotaxy (29/44, $65.9 \%)$ and double-outlet right ventricle (23/44, 52.3\%). 


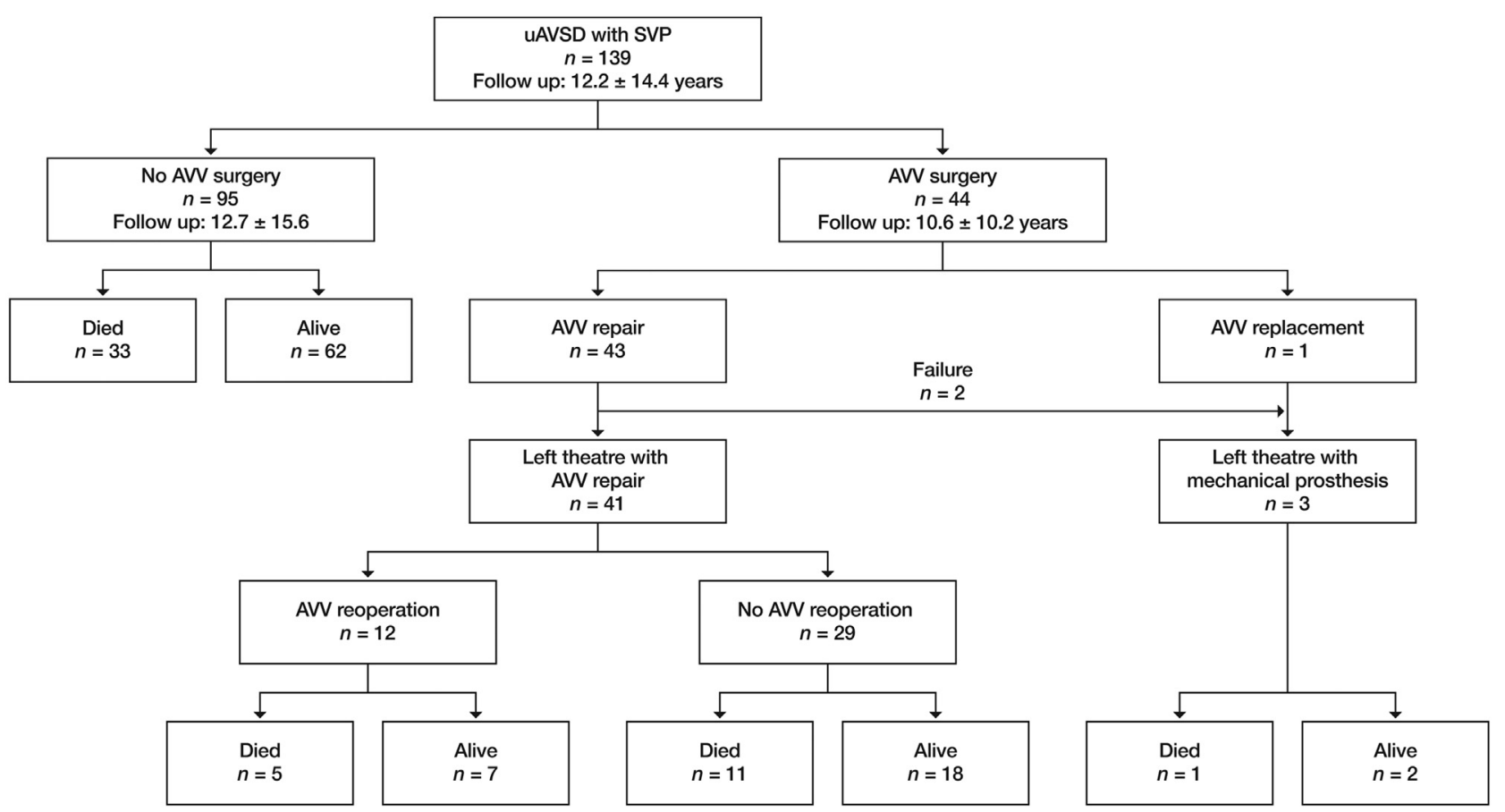

FIGURE 1. Consort diagram demonstrating outcomes after AVV repair in patients with uAVSD. $u A V S D$, Unbalanced atrioventricular septal defect; $S V P$, single-ventricle palliation; $A V V$, atrioventricular valve.

Preoperative echocardiographic AVVR grade was recorded in $86.4 \%$ of patients (38/44), of whom $84.2 \%(32 / 38)$ had moderate or greater AVVR.

\section{Mechanism of Regurgitation}

It was possible to determine the mechanism of AVV regurgitation for $79.5 \%$ of patients (35/44). The mechanisms of AVVR were central regurgitation with annular dilatation $(42.9 \%, 15 / 35)$, central regurgitation with leaflet dysplasia $(22.9 \%, 8 / 35)$, eccentric regurgitation due to prolapse of 1 or more leaflets $(31.4 \%, 11 / 35)$, and eccentric regurgitation due to leaflet restriction $(2.9 \%, 1 / 35)$.

\section{Techniques of Repair}

The techniques used for AVV repair are summarized in Table 2. Repair of the AVV was attempted in $97.7 \%(43 / 44)$ of patients. The most commonly used techniques were annuloplasty $(31.8 \%, 14 / 44)$ and edge-to-edge repair $(54.5 \%, 24 / 44)$, which included facilitation with an ePTFE bridge in $18.2 \%$ (8/44). In 2 patients $(4.5 \%, 2 / 44)$ who initially underwent annuloplasty, repair was unsuccessful and conversion to mechanical AVV replacement was performed in the same procedure. Direct mechanical valve replacement was performed in 1 patient $(2.3 \%, 1 / 44)$. Mean cross-clamp time was $78.6 \pm 37.6$ minutes, and mean cardiopulmonary bypass time was $159.0 \pm 73.7$ minutes.

\section{Early Outcomes}

Early mortality was $18.2 \%(8 / 44)$. A predischarge transthoracic echocardiogram was performed for $85.4 \%$ (35/41) of children who underwent AVV repair. Mild or less AVV regurgitation was recorded in $62.9 \%$ (22/35), and $37.1 \%$ $(13 / 35)$ of patients had moderate regurgitation. The mean grade of AVVR in patients who had AVV repair decreased from $3.1 \pm 0.4$ preoperatively to $2.4 \pm 0.9$ at discharge $(P<.001)$. Early permanent pacemaker implantation was required in $13.6 \%(6 / 44)$ of patients.

\section{Late Outcomes}

Mean follow-up time was $10.6 \pm 10.2$ years (median, 7.4 years; interquartile range, 2.2-15.4 years). Follow-up was complete for all patients.

The Kaplan-Meier survival function is shown in Figure 2, $A$, whereas the competing risk model of survival is shown in Figure 3, A. Freedom from death and transplantation at 10 years was $66.0 \%$ (95\% confidence interval $[\mathrm{CI}], 49.1-78.5)$ and at 20 years was $53.3 \%(95 \%$ CI, 32.1-70.6).

Kaplan-Meier freedom from AVV reoperation is shown in Figure 2, $B$, whereas the competing risk model for freedom from reoperation is shown in Figure $3, B$. Freedom from AVV reoperation at 10 years was $61.9 \%$ (95\% CI, 41.9-76.8) and at 20 years was 56.3\% (95\% CI, 35.3-72.8). 
TABLE 1. Demographic data at initial atrioventricular valve repair

\begin{tabular}{|c|c|}
\hline Total & 44 \\
\hline Age (y) & 3.0 (IQR, 0.7-4.4) \\
\hline \multicolumn{2}{|l|}{ Sex, n $(\%)$} \\
\hline Male & $28(63.6)$ \\
\hline Female & $16(36.4)$ \\
\hline \multicolumn{2}{|l|}{ Ventricular dominance, $\mathrm{n}(\%)$} \\
\hline Left & $11(25.0)$ \\
\hline Right & $28(63.6)$ \\
\hline 2 balanced ventricles & $5(11.4)$ \\
\hline \multicolumn{2}{|l|}{ Associated diagnoses, n (\%) } \\
\hline Heterotaxy & $29(65.9)$ \\
\hline Double-outlet right ventricle & $23(52.3)$ \\
\hline TGA & $13(29.5)$ \\
\hline TAPVD & $13(29.5)$ \\
\hline Aortic arch hypoplasia & $5(11.4)$ \\
\hline Aortic atresia & $2(4.5)$ \\
\hline \multicolumn{2}{|l|}{ Chromosomal anomalies, n (\%) } \\
\hline DiGeorge syndrome & $1(2.3)$ \\
\hline Noonan syndrome & $1(2.3)$ \\
\hline Other & $1(2.3)$ \\
\hline \multicolumn{2}{|l|}{ Ventricular dysfunction } \\
\hline Moderate or greater & $5(11.4)$ \\
\hline Mild or less & $28(63.6)$ \\
\hline Not recorded & $11(25.0)$ \\
\hline \multicolumn{2}{|l|}{ Preoperative AVVR, n (\%) } \\
\hline Mild to moderate & $6(14)$ \\
\hline Moderate & $21(48)$ \\
\hline Moderate to severe & $7(16)$ \\
\hline Severe & $4(9)$ \\
\hline Unknown & $6(14)$ \\
\hline \multicolumn{2}{|l|}{ Stage of palliation, $\mathrm{n}(\%)$} \\
\hline Before stage I & $1(2.3)$ \\
\hline At the time of stage I & $1(2.3)$ \\
\hline Between stage I and II & $5(11.4)$ \\
\hline At the time of stage II & $16(36.4)$ \\
\hline Between stage II and Fontan & $9(20.4)$ \\
\hline At the time of Fontan & $10(22.7)$ \\
\hline After Fontan & $2(4.5)$ \\
\hline \multicolumn{2}{|l|}{ Initial stage I palliation, $\mathrm{n}(\%)$} \\
\hline RMBT & $14(31.8)$ \\
\hline Central shunt & $6(13.6)$ \\
\hline PA band & $6(13.6)$ \\
\hline Norwood & $3(6.8)$ \\
\hline Pulmonary valvuloplasty & $1(2.3)$ \\
\hline Proceeded directly to stage II & $10(22.7)$ \\
\hline Proceeded directly to Fontan & $4(9.1)$ \\
\hline
\end{tabular}

$I Q R$, Interquartile range; TGA, transposition of great arteries; TAPVD, total anomalous pulmonary venous drainage; $A V V R$, atrioventricular valve repair; $R M B T$, right modified Blalock-Taussig shunt; $P A$, pulmonary artery.

A total of 3 patients underwent orthotopic cardiac transplantation, 2 of whom subsequently died at 22 days and 13.9 years after transplantation, respectively. The surviving patient was 1.2 years post-transplantation at the time of the most recent follow-up.
TABLE 2. Techniques of atrioventricular valve surgery

\begin{tabular}{|c|c|}
\hline \multicolumn{2}{|c|}{ Techniques for first AVV operation, $\mathrm{n}(\%)$} \\
\hline Annuloplasty & $14(31.8)$ \\
\hline Isolated de Vega & $9(20.5)$ \\
\hline de Vega with cleft closure & $3(6.8)$ \\
\hline de Vega with neochords & $1(2.3)$ \\
\hline Commissuroplasty & $2(4.5)$ \\
\hline Edge-to-edge & $24(54.5)$ \\
\hline Suture & $16(26.4)$ \\
\hline Isolated & $8(18.2)$ \\
\hline With cleft closure & $4(9.1)$ \\
\hline With annuloplasty & $3(6.8)$ \\
\hline $\begin{array}{l}\text { With neochord and } \\
\text { commisuroplasty }\end{array}$ & $1(2.3)$ \\
\hline ePTFE bridge & $8(18.2)$ \\
\hline Isolated & $1(2.3)$ \\
\hline With cleft closure & $6(13.6)$ \\
\hline With chordal shortening & $1(2.3)$ \\
\hline Chordal repair & $3(6.8)$ \\
\hline Isolated neochords & $1(2.3)$ \\
\hline With cleft closure & $2(4.5)$ \\
\hline Closure of AVV component & $2(4.5)$ \\
\hline Patch closure & $2(4.5)$ \\
\hline Replacement & $1(2.3)$ \\
\hline \multicolumn{2}{|c|}{ Techniques for second AVV operation, $\mathrm{n}(\%)$} \\
\hline Repair & $9(64.3)$ \\
\hline Edge-to-edge & $4(28.6)$ \\
\hline Suture & $3(21.4)$ \\
\hline ePTFE bridge & $1(7.1)$ \\
\hline Leaflet patch augmentation & $3(21.4)$ \\
\hline Annuloplasty & $2(14.3)$ \\
\hline Replacement & $5(35.7)$ \\
\hline
\end{tabular}

\section{Risk Factors for Death or Transplantation, and Reoperation}

The risk factors for death or transplantation, and AVV reoperation are shown in Table 3. In univariable analysis, age less than 1 year (subhazard ratio [SHR], 10.6; $P<.001$ ), having a repair before stage II palliation (HR, $4.5, P=.01)$, and having moderate or greater AVVR at discharge (SHR, 2.7; $P=.001$ ) were predictors of death or transplantation. In multivariable analysis, moderate or greater predischarge AVVR (SHR, 6.4; $P=.002$ ), age less than 1 year (HR, $8.3 ; P=.03)$, and repair before stage II (SHR, 3.4; $P=.04$ ) were associated with a higher risk of death or transplantation. Significant AVVR at discharge was the only risk factor associated with an increased risk of AVV reoperation (SHR, $1.8 ; P=.03$ ).

Kaplan-Meier curves for freedom from death and transplantation comparing infants with children aged more than 1 year are shown in Figure 4, A. Freedom from death and transplantation at 5 years was $86.1 \%(95 \% \mathrm{CI}$, 67.0-94.5) in those aged more than 1 year, compared with $19.4 \%(95 \% \mathrm{CI}, 3.5-45.0)$ in infants $(P<.001)$. 


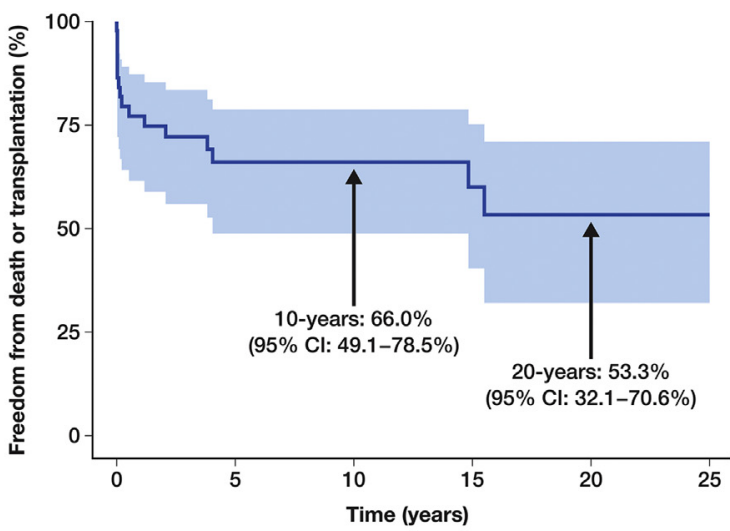

A
20

14
10

FIGURE 2. Kaplan-Meier curves for (A) freedom from death and transplantation

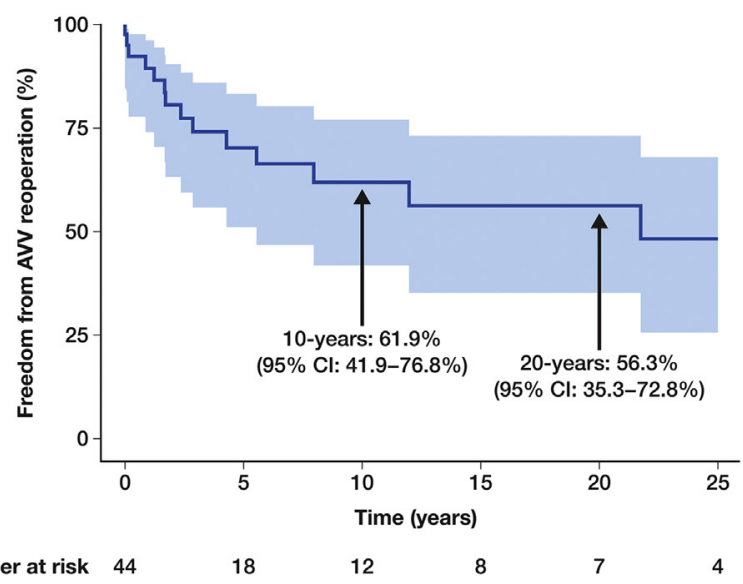

$C I$, Confidence interval; $A V V$, atrioventricular valve.

Kaplan-Meier curves for freedom from death and transplantation comparing patients with significant AVVR at discharge with patients who did not have significant AVVR are shown in Figure 4, B. The 5-year freedom from death and transplantation for the group without significant AVVR at discharge was $78.8 \%$ (95\% CI, 52.3-91.6), compared with $33.0 \%$ (95\% CI, 9.2-59.7) for the group with significant AVVR $(P<.001)$. The 5-year freedom from reoperation was $84.4 \% \quad(95 \%$ CI, 58.9-94.7) for the group without significant AVVR at discharge, whereas all patients with significant AVVR had undergone AVV reoperation $(P<.001)$.

Freedom from death and transplantation of children aged more than 1 year comparing those with significant AVVR at discharge with children without significant AVVR is shown in Figure 4, $C$. The 5-year freedom from death and transplantation for the group without significant AVVR was
$100.0 \%$ compared with $50.0 \%(95 \%$ CI, $11.1-80.4)$ for the group with significant $\operatorname{AVVR}(P=.003)$.

Freedom from death and transplantation of infants comparing those with significant AVVR at discharge with children without significant AVVR is shown in Figure 4, $D$. The 2-year freedom from death and transplantation for the group without significant AVVR was $71.4 \%(95 \% \mathrm{CI}$, 25.8-92.0), compared with $28.6 \%$ (95\% CI, 4.1-61.2) for the group with significant AVVR $(P=.04)$.

\section{Outcomes of Atrioventricular Valve Replacement}

A total of 8 patients underwent AVV replacement (3 as first AVV operation, 2 as second AVV operation, and 3 as third AVV operation). Kaplan-Meier freedom from death and transplantation is shown in Figure 5. Freedom from death and transplantation was $75.0 \%$ (95\% CI, 31.5-93.1) at 10 years. Only 1 of these children was an infant at the
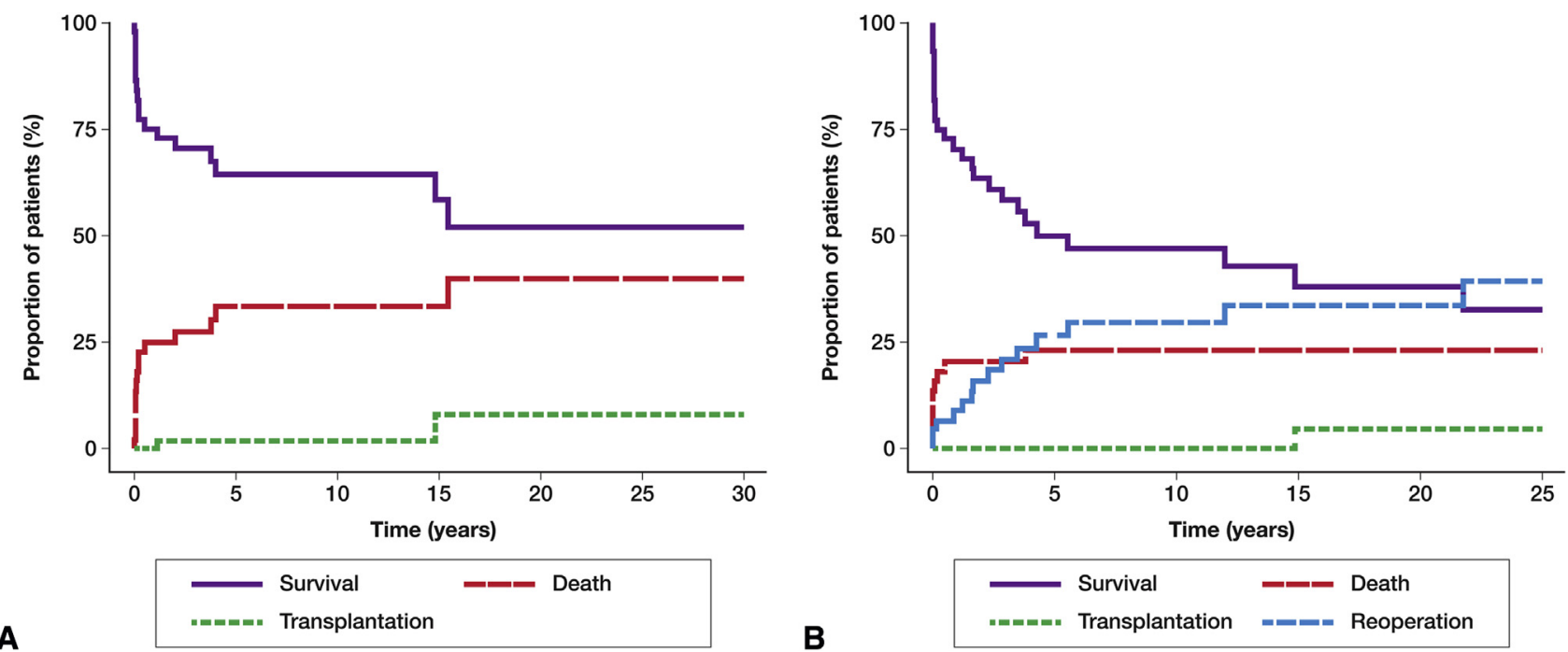

FIGURE 3. Competing risk models (A) for survival and (B) for reoperation on the AVV after AVV repair in patients with uAVSD. 
TABLE 3. Risk factors for death and reoperation

\begin{tabular}{|c|c|c|c|c|}
\hline \multirow[b]{2}{*}{ Univariable predictor } & \multicolumn{2}{|c|}{ Mortality } & \multicolumn{2}{|c|}{ Reoperation } \\
\hline & $\begin{array}{c}\text { SHR } \\
(95 \% \text { CI })\end{array}$ & $\begin{array}{c}P \\
\text { value }\end{array}$ & $\begin{array}{c}\text { SHR } \\
(95 \% \text { CI })\end{array}$ & $\begin{array}{c}P \\
\text { value }\end{array}$ \\
\hline Age $<1$ y & $10.6(2.7-41.6)$ & .001 & $1.0(0.3-3.3)$ & .98 \\
\hline Dominant RV & $1.2(0.42-3.4)$ & .) .73 & $1.5(0.48-4.8)$ & .47 \\
\hline Edge-to-edge repair & $2.4(0.79-7.4)$ & ).12 & $1.7(0.64-4.6)$ & .28 \\
\hline ePTFE bridge technique & $0.74(0.18-3.0)$ & ) .67 & $2.1(0.57-7.9)$ & .26 \\
\hline Repair before stage II & $4.5(1.6-12.7)$ & ).004 & $0.77(0.10-6.0)$ & .81 \\
\hline $\begin{array}{l}\text { Significant predischarge } \\
\text { AVVR }\end{array}$ & $2.7(1.4-10.2)$ & .01 & $18(1131)$ & .03 \\
\hline $\begin{array}{l}\text { Significant preoperative } \\
\text { AVVR }\end{array}$ & $2.0(0.7-6.0)$ & .22 & $2.0(0.40-10.0)$ & .40 \\
\hline TAPVD & $0.77(0.18-3.3)$ & ).74 & $0.41(0.06-3.1)$ & .39 \\
\hline Ventricular dysfunction & $1.4(0.2-8.3)$ & 69 & * & * \\
\hline Year of procedure & $0.99(0.94-1.0)$ & ) .61 & $1.03(0.97-1.1)$ & .32 \\
\hline \multicolumn{2}{|c|}{ Multivariable predictor } & \multicolumn{2}{|c|}{ HR $(95 \%$ CI $)$} & value \\
\hline $\begin{array}{l}\text { Significant predischarge } \\
\text { AVVR }\end{array}$ & & \multicolumn{2}{|c|}{$6.4(1.9-20.9)$} & .002 \\
\hline Age $<1$ y & & \multicolumn{2}{|c|}{$8.3(1.1-49.8)$} & .01 \\
\hline Repair before stage II & & \multicolumn{2}{|c|}{$3.4(1.1-10.7)$} & .04 \\
\hline
\end{tabular}

Bold indicates statistical significance. $S H R$, Subhazard ratio; $C I$, confidence interval; $R V$, right ventricle; $e P T F E$, expanded polytetrafluoroethylene; $A V V R$, atrioventricular valve regurgitation; TAPVD, total anomalous pulmonary venous drainage; $H R$, hazard ratio. *Insufficient number of events precludes analysis.

time of AVV replacement and died 15 years after replacement.

Re-replacement was required in 3 patients; in 2 cases this was due to functional stenosis resulting from patient growth (6 and 12 years after replacement, respectively). In 1 patient, re-replacement was required due to thrombosis causing immobility of 1 leaflet, 4 years after implantation.

\section{Reoperations}

A total of 14 patients $(14 / 44,31.8 \%)$ underwent an AVV reoperation. The mean time from initial AVV operation to reoperation was $4.1 \pm 6.0$ years (median, 2.0 years; interquartile range, 0.9-4.3 years).

Of the 14 patients requiring reoperation, $85.7 \%(12 / 14)$ had undergone initial AVV repair, whereas $14.3 \%$ patients $(2 / 14)$ had undergone replacement. The mechanism of AVVR for the patients who underwent initial AVV repair could be determined for $91.7 \%$ (11/12) of patients. The mechanism of AVVR was central regurgitation due to annular dilatation $(63.6 \%, 7 / 11)$, eccentric regurgitation due to leaflet prolapse $(18.2 \%, 2 / 11)$, central regurgitation due to leaflet dysplasia $(9.1 \%, 1 / 11)$, and dehiscence of a previous repair $(9.1 \%, 1 / 11)$.

The techniques used to perform reoperation are summarized in Table 2. Repair was performed in $64.3 \%$ (9/14) of patients, and replacement was performed in
$35.7 \%$ (5/14) of patients. The most commonly used techniques for re-repair were edge-to-edge repair $(21.4 \%$, $3 / 14)$ and patch augmentation of a leaflet $(21.4 \%, 3 / 14)$.

Early mortality after reoperation on the AVV was $7.1 \%$ (1/14). Freedom from death and transplantation after AVV reoperation was $76.2 \%(95 \% \mathrm{CI}, 42.7-91.7)$ at 1 year and $55.5 \%(95 \%$ CI, 22.8-79.1) at 5 and 10 years. Freedom from reoperation after AVV reoperation was $78.6 \%(95 \%$ $\mathrm{CI}, 47.3-92.5)$ at 1 year and $68.8 \%(95 \% \mathrm{CI}, 35.7-87.3)$ at 5 and 10 years.

\section{Status at Last Follow-up}

There were 26 transplant-free survivors $(26 / 44,59.1 \%)$ at most recent follow-up. Fontan completion had been achieved in $84.6 \%(22 / 26)$, whereas $15.4 \%(4 / 26)$ were awaiting Fontan completion. A transthoracic echocardiogram was performed at last follow-up for $96.1 \%(25 / 26)$ of transplant-free survivors, of whom the grade of AVVR was less than moderate in $60.0 \%(15 / 25)$, moderate in $32.0 \%(8 / 25)$, and severe in $8.0 \%(2 / 25)$. The New York Heart Association functional status was available for all patients who achieved Fontan completion, of whom $81.8 \%(18 / 22)$ were in class I and $13.6 \%(3 / 22)$ were in class II. One patient $(1 / 22,4.5 \%)$ was in class III with severe AVVR and awaiting AVV replacement.

\section{DISCUSSION}

Children with uAVSD who require SVP are challenging to manage, with substantial early mortality and less than $60 \%$ survival at 20 years. ${ }^{2,3}$ One of the risk factors for mortality in children with uAVSD is significant AVVR. ${ }^{2,3}$

Owens and colleagues ${ }^{14}$ described 44 patients with uAVSD who presented between 1998 and 2003, of whom $79.5 \%$ (35/44) underwent SVP. Of these patients, $27.3 \%$ (12/44) required AVV surgery. The need for AVV surgery was associated with a significantly higher risk of mortality.

Likewise, our group recently published the outcomes of SVP for uAVSD in 139 patients who underwent surgery between 1976 and 2016. ${ }^{3}$ In this group, AVVR was associated with a significantly greater risk of death or transplantation.

Furthermore, it has been shown that AVVR is associated with increased risk of mortality in the overall population of patients undergoing SVP. ${ }^{4,15}$ A previous report from our group, which included 499 patients who underwent SVP between 1990 and 2008, identified AVVR as a risk factor for death. ${ }^{4}$ Likewise, Pundi and colleagues, ${ }^{15}$ in a cohort of 1052 patients who underwent a Fontan procedure between 1973 and 2012 demonstrated that AVV replacement was associated with an increased risk of death.

Achieving a successful repair of the AVV in patients with single-ventricle physiology is challenging, and residual AVVR is known to increase the risk of mortality. ${ }^{16,17}$ However, there are few reports of AVV repair techniques applied in the setting of uAVSD. 
$>1$ year of age ----

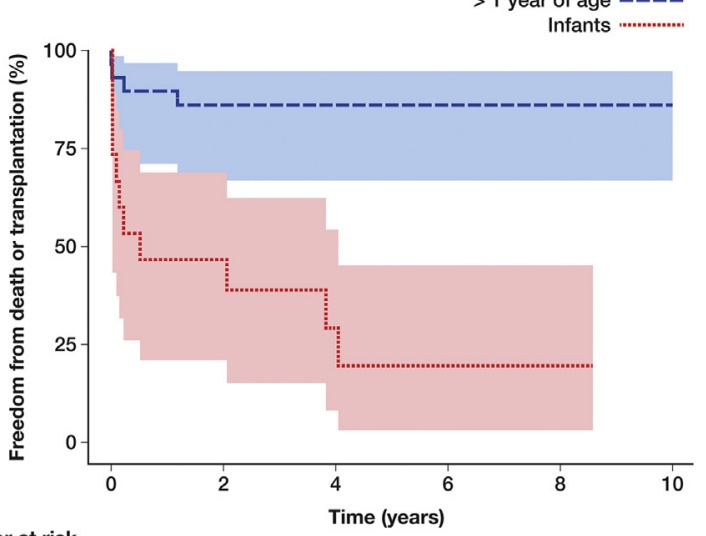

Number at risk $>1$ year 29

A

$\begin{array}{rcccccc}>1 \text { year } & 29 & 23 & 19 & 18 & 16 & 14 \\ \text { Infants } & 15 & 6 & 3 & 1 & 1 & 0\end{array}$

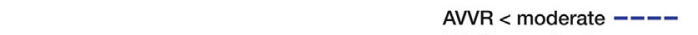

AVVR $<$ moderate - mon.
AVVR $\geq$ moderate

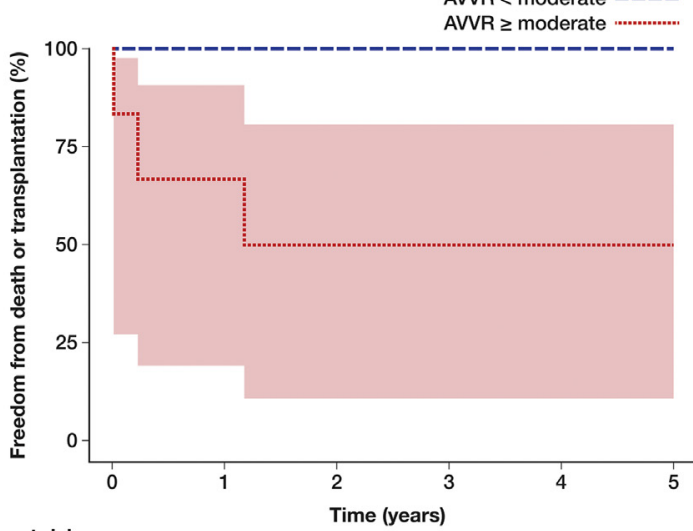

Number at risk AVVR < moderate

C AVVR $\geq$ moderate
Time (years)

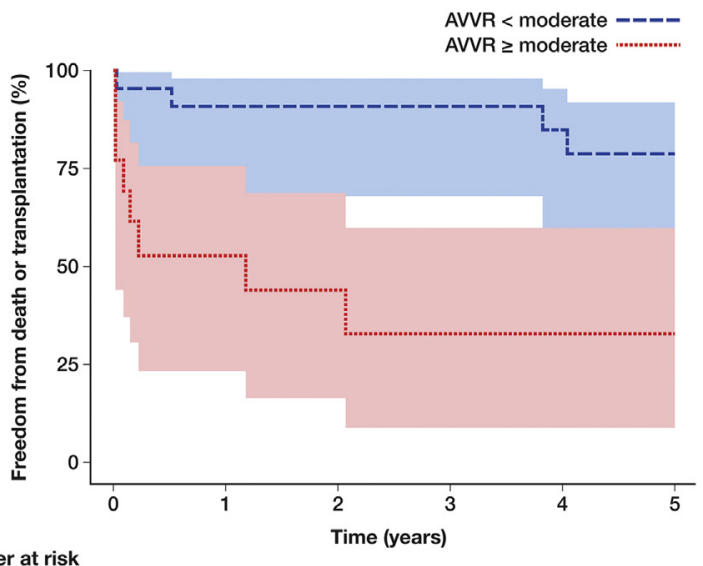

Number at risk $\begin{array}{llllccc}\text { AVVR }<\text { moderate } & 22 & 20 & 18 & 16 & 14 & 12\end{array}$

B

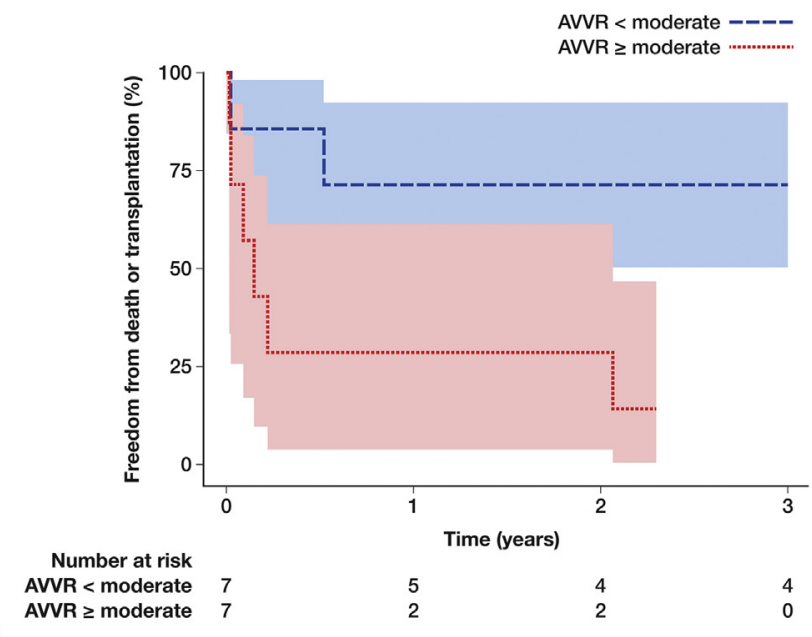

FIGURE 4. Kaplan-Meier curves for freedom from death or transplantation (A) comparing infants and those aged more than 1 year, (B) by degree of AVVR at the time of discharge from hospital, (C) for children aged more than 1 year by degree of AVVR at the time of discharge from hospital, and (D) for infants by degree of AVVR at the time of discharge. AVVR, Atrioventricular valve repair.

Misumi and colleagues ${ }^{11}$ reported on 38 patients with common AVV and SVP (25 with uAVSD), who required AVV surgery between 1995 and 2012. They demonstrated a 15 -year survival of $58.2 \%$ and 15 -year freedom from reoperation of $45.3 \%$, using an edge-to-edge repair facilitated with an ePTFE bridge. In their cohort, AVV surgery before bidirectional cavopulmonary shunt and the presence of total anomalous pulmonary venous drainage were risk factors for mortality.

Vijarnsorn and colleagues ${ }^{18}$ recently reported a cohort of 9 patients with uAVSD and univentricular physiology who underwent AVV repair from 2003 to 2012. In this small study, $66.7 \%(6 / 9)$ of patients had residual moderate or greater AVVR postoperatively. Of the 6 patients with residual moderate AVVR, 50\% (3/6) had died at 18 months follow-up.

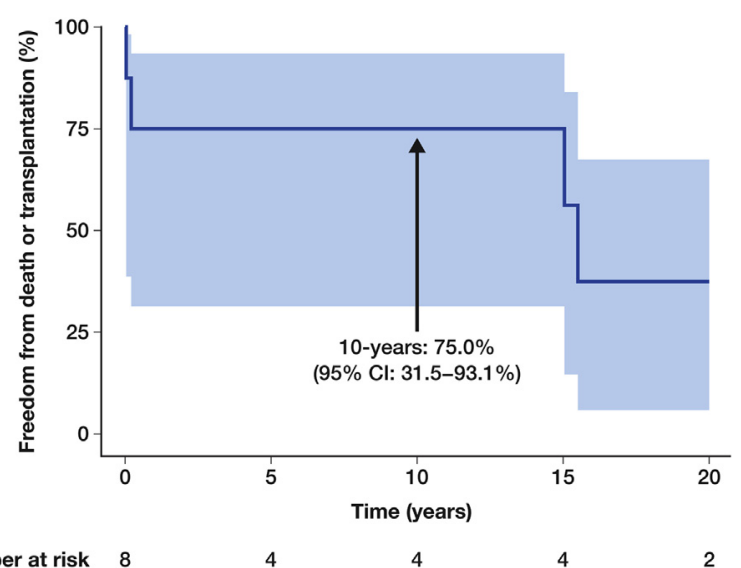

FIGURE 5. Freedom from death and transplantation following AVV replacement in patients with uAVSD. $C I$, Confidence interval. 
Imai and colleagues ${ }^{19}$ reported 28 patients with uAVSD and univentricular physiology who underwent concomitant AVV repair and Fontan procedure between 1985 and 1998. The techniques used in this series were circular suture annuloplasty and cleft closure, and they reported a decrease in the mean grade of AVVR from 1.8 to 0.6 after repair. This study did not describe early mortality or long-term survival of patients who underwent repair of their common AVV. Most importantly, it seems that Imai and colleagues ${ }^{19}$ described a subgroup of patients with a more favorable $\mathrm{AVV}$ anatomy that permitted survival to Fontan completion. We have previously observed that patients with uAVSD who survive to Fontan completion have favorable outcomes. ${ }^{3}$

Kotani and colleagues ${ }^{16}$ reported 66 patients with SVP who underwent AVV repair from 1998 to 2011, of whom 10 patients had uAVSD. The mean grade of AVVR decreased from 2.1 to 1.3 after repair. At 5 years follow up, freedom from reoperation was $75 \%$, whereas survival was $76 \%$. Significant residual AVVR on intraoperative echocardiography was associated with increased risk of reoperation.

We have previously described 76 patients who underwent SVP and AVV repair between 1988 and 2010 at The Royal Children's Hospital. Of these patients, 14 had uAVSD. ${ }^{5}$ In this group, the AVVR grade decreased from 3.3 to 2.3. Survival at 10 years was $61 \%$, and freedom from reoperation was $56 \%$. AVV surgery between initial palliation and stage II was associated with increased risk of mortality.

Compared with these results, our subgroup of patients with uAVSD had a mean preoperative AVVR grade of 3.1, whereas the mean postoperative degree of AVVR was 2.4. Although we demonstrated a significant improvement in AVVR after repair in patients with UAVSD, the residual degree of AVVR was greater than in the groups described. This is particularly important considering that moderate or greater AVVR at discharge was associated with a significantly higher risk of mortality and reoperation in our patients. Survival at 5 years was $79 \%$ in those without significant AVVR at discharge, compared with $33 \%$ in those with moderate or greater AVVR. In addition, although $84 \%$ of patients with less than moderate AVVR at discharge were free of reoperation at 5 years, all surviving patients with moderate or greater AVVR had required a reoperation over the same period. This suggests that AVV competency is more difficult to achieve in UAVSD compared with other forms of SVP. Furthermore, failure to achieve a satisfactory repair was associated with poor outcomes. Likewise, others have shown that significant postoperative AVVR in patients with SVP was associated with poorer survival and higher rates of reoperation. ${ }^{16,17}$

The risk of leaving residual AVVR must be balanced against the risks associated with AVV replacement. In our unit, there has been a strong preference to repair the AVV because of the perceived risks of AVV replacement in children. However, Jang and colleagues, ${ }^{12}$ in a cohort of 33 patients with SVP undergoing AVV surgery, demonstrated that AVV replacement was associated with a significantly lower rate of reoperation when compared with patients undergoing repair. Furthermore, the actuarial survival was $20 \%$ greater in the replacement group at 7 years follow-up, although this did not reach significance. Mahle and colleagues ${ }^{20}$ in a cohort of 17 children with SVP, who underwent AVV replacement at a mean age of 3 years, demonstrated 5-year survival of $75 \%$ in the recent era. In our cohort, the 10-year freedom from death and transplantation after AVV replacement was $75 \%$, which is slightly better than the overall cohort, although direct comparison cannot be made as some of these AVV replacements were performed as a reoperation. Furthermore, it should be noted that only 1 of these patients was an infant. Thus, it may be better to replace the AVV when less than moderate AVVR cannot be achieved with repair, especially because a relatively large prosthesis can be implanted in children with uAVSD due to the common AVV. In the past, we tended to accept moderate AVVR, with close clinical follow-up. However, our data, presented in the current article, indicate that if infants are left with moderate or greater AVVR at the time of discharge from the hospital, they do poorly. Thus, it would be reasonable to replace AVV in these infants.

In addition to significant AVVR at discharge, AVV repair in infancy was associated with a higher risk of mortality in multivariable analysis. Moreover, there was increased mortality when AVV repair was performed before stage II palliation. This would suggest that in patients with uAVSD, earlier surgery is associated with higher risk. Indeed, a similar trend was observed in the overall population with SVP. ${ }^{5}$ It is likely that children who required AVV repair earlier had more severe dysplasia of AVV, and this contributed to their poorer outcomes.

Despite the high rate of reoperations for AVVR and the fact that $40 \%$ of patients had moderate or greater AVVR, $96 \%$ of surviving patients who achieved Fontan completion were in New York Heart Association functional class I or II at most recent follow-up. This is consistent with results previously reported for the general population with univentricular physiology. 3,21

Given the challenge associated with AVV repair in patients with uAVSD, several techniques have been used. In the early part of the series, de Vega annuloplasty was used for the majority of repairs. However, our group has previously shown that this technique was associated with poor results. ${ }^{5}$ The edge-to-edge repair was used in many patients, but likewise has been shown to be an unreliable technique. ${ }^{8,9}$ In more recent years, we used an ePTFE bridge to support edge-to-edge repairs, with the aim of providing apposition of the bridging leaflets and annular 
stabilization. ${ }^{8-10}$ Because the mechanism of AVVR is most frequently central regurgitation, related to annular dilatation or failure of the bridging leaflets to coapt properly, the PTFE bridge has been developed in an attempt to stabilize the annulus and support the bridging leaflets, while still allowing annular growth. Further follow-up will demonstrate if it is able to achieve this goal.

\section{Study Limitations}

This study is limited by its small sample size and retrospective nature. Particularly, the subgroup analysis of survival based on age and degree of AVV regurgitation at discharge were limited by small numbers of patients, and this must be kept in mind when interpreting the results. Furthermore, this study includes operations performed over a 40-year period, during which surgical techniques have changed. Also, ventricular function could not be assessed in all patients because echocardiography was not available in the early part of the study. Nevertheless, this represents the largest series of AVV repairs in patients who have undergone SVP for UAVSD published to date.

\section{CONCLUSIONS}

AVV repair in patients with uAVSD who have undergone SVP is associated with a substantial risk of reoperation and mortality. Achieving a competent valve is difficult, but important, because those with significant residual AVVR are at a greater risk of death and reoperation. Infants with residual AVVR represent a particularly high-risk group. When a satisfactory repair cannot be achieved, AVV replacement may be the better strategy.

\section{Conflict of Interest Statement}

C.P.B. serves on the advisory board of Admedus. Y.d'U. is a consultant for Actelion and MSD. All other authors have nothing to disclose with regard ro commercial support.

\section{References}

1. Cohen MS, Spray TL. Surgical management of unbalanced atrioventricular canal defect. Semin Thorac Cardiovasc Surg Pediatr Card Surg Ann. 2005;8:135-44.

2. Drinkwater DC Jr, Laks H. Unbalanced atrioventricular septal defects. Semin Thorac Cardiovasc Surg. 1997:9:21-5.

3. Buratto E, Ye XT, King G, Shi W, Brizard CP, d'Udekem Y, et al. Long-term outcomes of single ventricle palliation for unbalanced atrioventricular septal defects: Fontan survivors do better than previously thought. J Thorac Cardiovasc Surg. 2017;153:430-8.
4. d'Udekem Y, Xu MY, Galati JC, Lu S, Iyengar AJ, Konstantinov IE, et al. Predictors of survival after single-ventricle palliation: the impact of right ventricular dominance. J Am Coll Cardiol. 2012;59:1178-85.

5. Wong DJ, Iyengar AJ, Wheaton GR, Ramsay JM, Grigg LE, Horton S, et al. Long-term outcomes after atrioventricular valve operations in patients undergoing single-ventricle palliation. Ann Thorac Surg. 2012;94:606-13.

6. Liu VJ, Yong MS, d'Udekem Y, Weintraub RG, Praporski S, Brizard CP, et al. Outcomes of atrioventricular valve operation in patients with Fontan circulation. Ann Thorac Surg. 2015;99:1632-8.

7. Ando M, Takahashi Y. Edge-to-edge repair of common atrioventricular or tricuspid valve in patients with functionally single ventricle. Ann Thorac Surg. 2007;84:1571-6.

8. Takayama T, Nagata N, Miyairi T, Abe M, Koseni K, Yoshimura Y. Bridging annuloplasty for common atrioventricular valve regurgitation. Ann Thorac Surg. 1995;59:1003-5.

9. Sughimoto K, Konstantinov IE, Brizard CP, d'Udekem Y. Polytetrafluoroethylene bridge for atrioventricular valve repair in single-ventricle palliation. J Thorac Cardiovasc Surg. 2015;149:641-3.

10. Konstantinov IE, Sughimoto K, Brizard CP, d'Udekem Y. Single ventricle: repair of atrioventricular valve using the bridging technique. Multimed Man Cardiothorac Surg. 2015;16:2015.

11. Misumi Y, Hoashi T, Kagisaki K, Kitano M, Kurosaki K, Shiraishi I, et al Long-term outcomes of common atrioventricular valve plasty in patients with functional single ventricle. Interact Cardiovasc Thorac Surg. 2014;18:259-65.

12. Jang WS, Kim WH, Choi K, Lee JR, Kim YJ, Kwon BS, et al. What factors predict long-term survival and valve durability in patients with atrioventricular valve regurgitation in single-ventricle physiology? Pediatr Cardiol. 2013;34: 1366-73.

13. Brizard CP. Mitral valve repair in children. In: Kaiser PL, Kron IL, Spray TL, eds Mastery of Cardiothoracic Surgery. Philadelphia: Lippincott and Williams; 2014:1105-17.

14. Owens GE, Gomez-Fifer C, Gelehrter S, Owens ST. Outcomes for patients with unbalanced atrioventricular septal defects. Pediatr Cardiol. 2009;30:431-5.

15. Pundi KN, Johnson JN, Dearani JA, Pundi KN, Li Z, Hinck CA, et al. 40-year follow-up after the Fontan operation: long-term outcomes of 1,052 patients. J Am Coll Cardiol. 2015;66:1700-10.

16. Kotani Y, Chetan D, Atlin CR, Mertens LL, Jegatheeswaran A, Caldarone CA, et al. Longevity and durability of atrioventricular valve repair in single-ventricle patients. Ann Thorac Surg. 2012;94:2061-9.

17. Lee TM, Aiyagari R, Hirsch JC, Ohye RG, Bove EL, Devaney EJ. Risk factor analysis for second-stage palliation of single ventricle anatomy. Ann Thorac Surg. 2012;93:614-8.

18. Vijarnsorn C, Khoo NS, Tham EB, Colen T, Rebeyka IM, Smallhorn JF Increased common atrioventricular valve tenting is a risk factor for progression to severe regurgitation in patients with a single ventricle with unbalanced atrioventricular septal defect. J Thorac Cardiovasc Surg. 2014;148:2580-8.

19. Imai Y, Seo K, Terada M, Aoki M, Shin'oka T, Ohta J, et al. Valvular repair for atrioventricular regurgitation in complex anomalies in modified Fontan procedure with reference to a single ventricle associated with a common atrioventricular valve. Semin Thorac Cardiovasc Surg Pediatr Card Surg Annu. 1999;2:5-19.

20. Mahle WT, Gaynor JW, Spray TL. Atrioventricular valve replacement in patients with a single ventricle. Ann Thorac Surg. 2001;72:182-6.

21. Hirsch JC, Goldberg C, Bove EL, Salehian S, Lee T, Ohye RG, et al. Fontan operation in the current era: a 15-year single institution experience. Ann Surg. 2008;248:402-10.

Key Words: atrioventricular valve, Fontan, single-ventricle palliation, unbalanced atrioventricular septal defect 